\title{
O SILÊNCIO DO ANJO
}

\section{THE SILENCE OF THE ANGEL}

Ana Maria Portugal Saliba*

Escola Letra Freudiana (ELF)

\begin{abstract}
RESUMO
A partir de ensaios de W. G. Sebald que discorrem sobre o silêncio dos escritores alemães no período pós-guerra, colocase a pergunta sobre essa ausência da escrita numa cultura de grande expressão e tradição literárias. Essa questão do silêncio diante do horror é ampliada para o campo da psicanálise e articulada à expressão "paixão pelo real", forjada pelo filósofo Alain Badiou, que propõe diante disso uma "via subtrativa".
\end{abstract}

PALAVRAS - CHAVE

W. G. Sebald, Alain Badiou, pós-guerra, escrita, silêncio, psicanálise

A psicanálise gera resistência e é uma arte da resistência e da negociação, mas também é uma arte da guerra e da representação teatral, intensa e única.

Ricardo Piglia

Foi por uma contingência que me encontrei com os textos de Winfried Georg Sebald, autor alemão (1944-2001). Sua obra tem sido objeto de estudos de críticos e estudiosos da literatura atual, tanto por pertencer a um gênero misto de ficção, memória e ensaio quanto por uma característica curiosa: em meio ao texto, incluem-se fotografias e imagens, nem sempre ilustrativas e acompanhadas de legendas, fazendo com que a leitura se suspenda e criando um enigma. O que faz aqui essa imagem? Faz parte do texto? Cria alguma alusão? É um tipo de intervenção? Teria uma função propulsora?

Nascido em Wertach (Allgäu, Alemanha) um ano antes do término da Segunda Guerra, estudou literatura em Freiburg e depois se instalou em Manchester, na Inglaterra, ingressando posteriormente na Universidade de East Anglia. Seus livros surgem na década de 1990 e, num tom de estranheza, entrelaçam ficção, depoimentos e memória.

Em 1997, quando convidado a fazer conferências sobre poética na Universidade de Zurique, Sebald aborda a dificuldade dos autores alemães em enfrentar o delicado tema da destruição das principais cidades do país pelos bombardeios dos Aliados na

\footnotetext{
*anamportugal@gmail.com
} 
Segunda Guerra Mundial. O tema das casas, das escolas e dos hospitais arrasados, bem como de centenas de desabrigados civis caminhando sem rumo pelas estradas, esse drama humano, está quase ausente da literatura alemã nos anos que se seguiram à catástrofe. $\mathrm{Ou}$, quando aparece, é tornado inócuo pela estilização expressionista ou pela retórica mística.

Essas conferências de Zurique foram reunidas - embora não exatamente como foram proferidas, esclarece o próprio autor quando as reuniu - e publicadas postumamente, em 2003, no volume Guerra aérea e literatura, no qual ele acrescenta a correspondência recebida logo após as tais conferências - textos "muitas vezes de caráter um tanto bizarro". ${ }^{1}$ Pela natureza deficiente e forçada dessas escritas recebidas, o autor pôde perceber que o que fora vivenciado no período pós-guerra nunca havia sido propriamente traduzido em palavras, sequer entre os diretamente atingidos, nem fora transmitido aos que nasceram depois. Nas palavras de Sebald:

Parece-me que nós, alemães, somos hoje um povo estranhamente cego para a história e despojado de tradição. Não temos um interesse apaixonado pelas nossas antigas formas de vida nem pelas especificidades de nossa própria civilização, como se nota, por exemplo, em toda a cultura da Grã-Bretanha. E quando olhamos para o passado, particularmente entre os anos de 1930 e 1950, trata-se sempre de um olhar e desviar de olhos simultâneos. A produção dos autores alemães depois da guerra é, por essa razão, muitas vezes determinada por uma consciência falsa ou parcial, formada para a consolidação da posição extremamente precária dos escritores numa sociedade quase na íntegra moralmente desacreditada. ${ }^{2}$

Referindo-se a sua infância e sua juventude, passada na região fronteiriça dos Alpes (em grande parte poupada dos efeitos imediatos das "operações bélicas"), o autor traz a sensação desse déficit, que no decurso dos anos se tornou para ele cada vez mais claro, escandaloso, pois cresceu com a sensação de que algo lhe era escondido em casa, na escola e também pelos escritores alemães, cujos livros lia na esperança de poder aprender mais sobre as monstruosidades dos bastidores de sua própria vida. A ideia de cidade - por exemplo, Munique, onde já estivera - se associava a um monte de escombros, paredes corta-fogo e buracos de janela pelos quais se via o vazio do ar.

Do lugarejo de Sonthofen, bastante destruído, para onde a família se mudou em 1950, Sebald se recorda de ruínas, que ele reconstrói com sua ficção. Conta que no anexo da estação terminal, cujo galpão principal era ocupado como depósito de uma companhia de eletricidade, às noites o professor de música Gogol dava aulas a alguns de seus alunos: "No inverno, em especial, era curioso ver como dentro de um único espaço iluminado desta casa arruinada os estudantes deslizavam seus arcos sobre violas e violoncelos, parecendo estar sentados a bordo de uma jangada que partiria dali rumo à escuridão".

Outra ruína mencionada era o chamado Herzschloss, um casarão da virada do século que só tinha intacta a cerca de ferro fundido do jardim e do porão. Nos anos 1950, o terreno já estava todo coberto de vegetação. Sebald relembra:

\footnotetext{
${ }^{1}$ SEBALD. Guerra aérea e literatura, p. 8.

${ }^{2}$ SEBALD. Guerra aérea e literatura, p. 8.

${ }^{3}$ SEBALD. Guerra aérea e literatura, p. 71.
} 
Nós crianças brincávamos nessa selva que surgira no centro do lugarejo. Recordo-me que nunca tive coragem suficiente de descer as escadas para os compartimentos do porão. Havia ali um cheiro de podridão e umidade, e eu sempre temia esbarrar com um cadáver de animal ou um corpo humano. ${ }^{4}$

No entanto - escreve ele -, não é preciso ir à Alemanha para ver o tempo da destruição. A maioria das bases aéreas da costa leste da Inglaterra, de onde saíram os bombardeios, ficou abandonada depois da guerra. "O mato cresceu sobre as pistas; as torres de controle, os bunkers, os barracões de lata despontam meio desmoronados na paisagem de aspecto um tanto fantasmagórico". ${ }^{5}$

Prossegue o autor:

São pontos em que a minha trajetória de vida se cruza com a história da guerra aérea. Em si, completamente desimportantes, eles não saíam porém da minha cabeça e me serviram de ensejo para finalmente seguir ao menos um pouco mais adiante na investigação dos motivos que levaram os autores alemães a não quererem ou não poderem descrever a destruição das cidades vivenciada por milhões de pessoas na Alemanha. Tenho plena consciência de que as minhas anotações nada sistemáticas não dão conta da complexidade do objeto. Creio, contudo, que mesmo na sua forma imperfeita elas abrem certa perspectiva para a maneira como a memória individual, coletiva e cultural lida com experiências que extrapolam o limite do suportável. ${ }^{6}$

Esses pontos insistentes e inquietantes na memória de Sebald surgem traduzidos em sua obra ficcional, a partir de "anotações nada sistemáticas" - em sua própria expressão - que, não pretendendo dar conta da complexidade do objeto, apresentam a construção de um estilo marcado de presença pessoal, enriquecida por uma atividade imaginativa contundente, muito próxima ao efeito real da experiência.

Sobre a costa leste da Inglaterra - de onde saíram os bombardeios dos Aliados na Segunda Guerra -, Sebald nos apresenta em outro livro, Os anéis de Saturno, dessa vez misto de memória, depoimento e ficção, um narrador que viaja ao longo da costa, margeando os pontos de alavanca da destruição, buscando restos, ruínas, castelos e residências meio ou totalmente abandonados, entrevistando famílias que expõem seus relatos de vida e de sobrevivência.?

Também em Austerlitz, Sebald constrói em forma romanesca um personagem marcado por uma sensação constante de deslocamento a buscar os fios de sua história, pois descobre ter sido criado por pais adotivos na Inglaterra, quando os seus biológicos foram enviados a campos de concentração. Suas viagens o levam a Praga e Paris, a campos de concentração, arquivos, museus e bibliotecas, onde analisa documentos, fotografias e vídeos. Sua busca obsessiva de tudo saber é, no entanto, barrada pelos desencontros desses documentos e pela estranheza desses objetos intemporais, levandoo a concluir: "Tudo isso compreendi então e também não compreendi, pois cada detalhe

\footnotetext{
${ }^{4}$ SEBALD. Guerra aérea e literatura, p. 71.

${ }^{5}$ SEBALD. Guerra aérea e literatura, p. 72.

${ }^{6}$ SEBALD. Guerra aérea e literatura, p. 73.

${ }^{7}$ SEBALD. Os anéis de Saturno.
} 
que se revelava para mim no meu caminho pelo museu, de uma sala a outra e de novo para trás, ultrapassava em muito a minha capacidade de compreensão". ${ }^{8}$

$\mathrm{Na}$ impossibilidade de compreensão, entretanto, o escritor Sebald escreve.

O contato com essa escrita ressoou para mim com uma pergunta, que implica numa questão para a psicanálise: diante do horror do real traumático, por que escrever? Por que não escrever?

Se pensamos que é preciso escrever, seria por uma pressão subjetiva ou por um dever sociocultural? Haveria aí, paradoxalmente, um impulso à transmissão, como no chiste, no dizer de Freud? Paradoxalmente porque, no processo do chiste, para que este se conclua, é necessária uma terceira pessoa, que, com seu riso, venha testemunhar o trabalho aliviador de suspensão do recalque e das repressões, obtido no jogo com o espírito (Witz) das palavras e das situações, ${ }^{9}$ ao passo que, diante do horror, o efeito é de perplexidade, de paralisação, de inibição, nem sempre sendo possível a escrita, ainda que o aspecto tenso da experiência persista e propulsione o sujeito a uma elaboração, que se manifesta em angústia.

Ou é preciso calar, porque não há o que dizer?

Ou então, como escreve o poeta Drummond, diante da verdade que só pode ser meio-dita, o possível é que cada um construa a outra metade da verdade com seu capricho, sua ilusão, sua miopia? ${ }^{10}$

Um autor que nos vem em ajuda é Alain Badiou, em seu livro O século (2007), no qual caracteriza o século XX - que ele limita entre a Primeira Guerra Mundial e a queda da URSS - com a expressão "paixão pelo real", provinda de dois elos possíveis entre os séculos XX e XIX: a finalidade ideal e a descontinuidade negativa. Por um lado, o que o século XIX pensou como finalidade ideal, a revolução, com que os utopistas e os primeiros marxistas sonharam, o século XX realiza; mas, em contraposição, numa descontinuidade negativa, o século XX renuncia a tudo o que o século XIX prometia: "O século XX é pesadelo, a barbárie de uma civilização desmoronada". ${ }^{11}$

Diz Badiou, parafraseando Jacques Lacan: "o século XX é o real daquilo cujo imaginário foi o século XIX; ou, ele é o real daquilo cujo simbólico foi o XIX (aquilo com que fez doutrina, aquilo que pensou, organizou)". ${ }^{12}$

De fato, na história do século XX, há certa exaltação do real até seu horror. Badiou considera que Lacan viu muito bem que a experiência do real é sempre, em parte, experiência do horror: "A verdadeira questão não é de maneira alguma a do imaginário, mas a de saber o que, nessas experimentações radicais, fazia ofício de real". ${ }^{13}$

Prossegue Badiou:

\footnotetext{
${ }^{9}$ FREUD. Os chistes e sua relação com o inconsciente, p. 166-167.

${ }^{10}$ ANDRADE. Corpo, p. 47.

${ }^{11}$ BADIOU. O século, p. 38.

${ }^{12}$ BADIOU. O século, p. 38.

${ }^{13}$ BADIOU. O século, p. 39.
} 
O século XX expõe o motivo da eficácia do desconhecimento, ao passo que o positivismo do século XIX afirmava o poder do conhecimento. Contra o otimismo cognitivo do positivismo, o século XX descobre e coloca em cena o extraordinário poder da ignorância, daquilo que Lacan nomeia com justa razão "paixão pela ignorância". ${ }^{14}$

Badiou acompanha as produções poéticas e artísticas do início e decorrer do século (Osip Mandelstam, Bertolt Brecht, Paul Celan, Luigi Pirandello, Kazimir Malevitch e outros). Para nós, analistas, é interessante destacar como o autor detecta os laços íntimos do real ao semblante, presente na máxima de "distanciamento" proposta por Brecht, a qual seria uma técnica para evidenciar, na própria atuação em cena do teatro, a distância entre esta e o real. Prossegue Badiou:

Mais profundamente, porém, consiste numa técnica de desmontagem dos laços íntimos e necessários que unem o real ao semblante, laços que resultam do fato de o semblante ser o verdadeiro princípio de situação do real, aquilo que localiza e torna visíveis os brutais efeitos da contingência do real. Uma das grandezas do século foi procurar pensar a relação, muitas vezes obscura num primeiro momento, entre violência real e aparente semblante, entre rosto e máscara, entre nudez e travestimento. ${ }^{15}$

Como se dá essa relação real/semblante e ao mesmo tempo, essa desmontagem?

Podemos entender que as palavras de Badiou se referem à necessidade do semblante para que possa ser situado o real, tornando visíveis os efeitos de sua contingência, efeitos que se descortinam na desmontagem dos artefatos de seu próprio encobrimento. "Fato não menos patente" - lembra Lacan - "que esse real provoque seu próprio desconhecimento, e inclusive produza sua negação sistemática". ${ }^{16}$

Certamente essa desmontagem não se dá de qualquer maneira, com qualquer ornamento ou arroubo da capacidade imaginativa, ou ainda com um simples documentário descritivo.

Em suas conferências, ao analisar as tentativas literárias produzidas, ainda que tardiamente, sobre a catástrofe da guerra, Sebald distingue aquelas que se traduzem por uma descrição objetiva e até mesmo cruel, de caráter a princípio documental, de outras que, com ornamentos exagerados ou alegorias da fantasia expressionista, roubam da literatura sua legitimação. ${ }^{17}$

Destaca o estilo documental de Hans Erick Nossack, que, a despeito de sua nefasta inclinação à lucubração filosófica e à falsa transcendência (por exemplo, em seu romance Nekya, relato de uma viagem ao reino dos mortos), tem o mérito de ter sido o único escritor de sua época a tentar redigir o que realmente vira na forma menos ornamentada possível. Escreve Sebald:

Ele se preocupa com os simples dados da realidade: com a estação do ano e o tempo, com a perspectiva do observador, com o ruído triturante da esquadrilha se aproximando, com o clarão vermelho no horizonte, com a condição física e psíquica dos que fugiram da cidade, com o cenário incendiado, com as chaminés que estranhamente permaneceram

\footnotetext{
${ }^{15}$ BADIOU. O século, p. 81.

${ }^{16}$ LACAN. Proposição sobre o psicanalista da escola, p. 30.

${ }^{17}$ SEBALD. Guerra aérea e literatura, p. 53.
} 
de pé, com as roupas que secam no varal diante da janela da cozinha, com uma cortina rasgada que balança ao vento na varanda vazia, com o sofá da sala e sua colcha de crochê e inúmeras outras coisas para sempre perdidas, e com o entulho sob o qual elas estão enterradas, com a terrível vida nova que se agita ali embaixo e a avidez repentina do ser humano por perfume. O imperativo moral de que pelo menos alguém tem que pôr no papel o que aconteceu naquela noite de julho em Hamburgo acarreta uma ampla renúncia a quaisquer exercícios estéticos. O relato é feito de maneira desapaixonada, como se falasse "de um acontecimento horrível do período pré-histórico". ${ }^{18}$

Dessas observações de Sebald, que acentuam no texto de Nossack os dados da realidade, num certo trabalho de depuração dos vestígios do real, podemos pensar algo sobre o laço real/semblante. São pequenos detalhes descritos sem muito ornamento que se por um lado são restos do real, por outro denunciam a posição de perplexidade do narrador com seu trabalho de ter de descrever tão detalhadamente, tão proximamente para se convencer de que o acontecimento é de fato real, e não pré-histórico.

São recursos de distanciamento que diferem de outras reações das pessoas no pósguerra - reações de negar o acontecido -, descritas por Alexander Kluge ao relatar a destruição de Halberstadt, sua cidade natal. Esse relato começa com a funcionária do cinema, Sra. Schrader, que, logo depois da queda de uma bomba, põe-se imediatamente a "limpar os escombros" na esperança de deixar o espaço arrumado para a sessão das 14 horas. No porão, onde encontra partes de corpos cozidas, arruma-as no tanque de roupa. Nossack, em seu retorno a Hamburgo, vê ainda outra mulher, limpando as janelas de uma casa que permanecera de pé em meio às ruínas. E ainda crianças limpando e arando um jardim. Pessoas numa sacada tomam seu café. "Era como um filme, no fundo era impossível". ${ }^{19}$

Outras reações de perplexidade, acompanhadas de um encobrimento que se desloca no tempo, são ainda apontadas por Kluge, que se recorda de ouvir a ópera Aída pela Rádio Roma na noite anterior ao ataque a Halberstadt. Outros sobreviventes ainda reforçam a lembrança da música ouvida nas vésperas do ataque, como se uma lembrança pudesse recobrir o horror da outra. "É uma associação entre a mais extrema profanidade e o sagrado, evocada aqui por uma experiência musical, é um artifício que se mantém até mesmo depois do fim", diz Sebald. ${ }^{20}$

Voltemos a Badiou, quando discutíamos os laços real/semblante e sua desmontagem, seguindo seu pensamento de que o século XX se caracteriza por uma "paixão pelo real", exaltada até seu horror, movimento que historicamente responde ao imaginário de século XIX, e que exige trabalho de depuração, labor intenso, lento e gradativo.

Esse trabalho de depuração visa a chegar à diferença mínima, é uma "via subtrativa", que difere do protocolo da destruição. Como no quadro de Malevitch Quadrado branco em fundo branco, obra que Badiou considera como um gesto muito próximo ao de Mallarmé na poesia: "a colocação em cena da diferença mínima, mas absoluta, a diferença entre o lugar e o que tem lugar no lugar, a diferença entre lugar e ter lugar”. ${ }^{21}$

\footnotetext{
${ }^{18}$ NOSSACK citado por SEBALD. Guerra aérea e literatura, p. 51-52.

${ }^{19}$ KLUGE; NOSSACK citado por SEBALD. Guerra aérea e literatura, p. 43-44.

${ }^{20}$ SEBALD. Guerra aérea e literatura, p. 45.

${ }^{21}$ BADIOU. O século, p. 93.
} 
Se o século XX foi o século da destruição por causa da "paixão pelo real”, Badiou, apoiado num poema de Malevitch (contemporâneo à composição de Quadrado branco), propõe acentuar a "via subtrativa" da diferença mínima, que possibilitaria manter a paixão pelo real, na qual uma verdade aparece como "interrupção", como "exceção radical", sem ceder aos encantos paroxísticos do terror e à destruição da realidade que, quanto ao real, o envolve e o oculta. ${ }^{22}$

São densas as palavras de Malevitch:

Lava teu ouvido, apaga os dias antigos, somente assim serás mais sensível e mais branco, porque mancha sombria eles jazem sobre teus hábitos na sabedoria e no sopro da vaga se traçará para ti o novo.

Teu pensamento encontrará os contornos, imprimirá o selo de tua caminhada. ${ }^{23}$

Essa proposta de Badiou da "via subtrativa" diante da "paixão do real" me faz voltar às conferências de Sebald, em sua investigação quanto ao silêncio dos autores alemães sobre o tempo da destruição, como se tivesse havido um acordo tácito e válido igualmente para todos.

Teria o silêncio entrado no lugar da "via subtrativa", pelo excesso de horror vivido na experiência? Ou estamos diante de um silêncio necessário, capaz de garantir certo distanciamento?

Citando Sebald:

Os aspectos mais sombrios do ato final da destruição, vivenciado em conjunto pela ampla maioria da população alemã, permaneceram um segredo familiar tão vergonhoso, submetido a uma espécie de tabu, que não se podia confessá-lo, quiçá, nem a si próprio. De todas as obras literárias surgidas no fim dos anos 40, apenas o romance de Heinrich Böll, O anjo silencioso, ${ }^{24}$ oferece uma ideia aproximada da dimensão do horror, que ameaçava tomar conta de qualquer um que realmente olhasse para as ruínas ao seu redor. Sua leitura deixa claro que justo esse texto, que parece contaminado por uma melancolia sem cura, seria intolerável para os leitores da época, como a editora e certamente o autor acreditaram, vindo, por isso a ser publicado somente em 1992, com quase cinquenta anos de atraso. ${ }^{25}$

Na década de 1990, surgiram outras raras publicações: Interview mit dem Tode (Entrevista com a morte), de Nossack; Europa in Trümmern (Europa em destroços), de Hans Magnus Enzensberg; Unheimlichkeit der Zeit (Estranheza do tempo), de Kluge.

Foi preciso um tempo de silêncio.

Hans, personagem de $\mathrm{O}$ anjo silencioso, de Heinrich Böll, retornando a Colônia após a guerra, em meio aos escombros, sente ansioso a presença de alguém, que, no

\footnotetext{
${ }^{22}$ BADIOU. O século, p. 106.

${ }^{23}$ MALEVITCH citado por BADIOU. O século, p. 94.

${ }^{24}$ Heinrich Böll (1917-1985) teve várias publicações nesse intervalo, tendo recebido prêmios, inclusive o Nobel de Literatura, em 1972.

${ }^{25}$ SEBALD. Guerra aérea e literatura, p. 19.
} 
entanto, não se movia. Mesmo quando percebeu que se tratava de uma estátua, as batidas de seu coração não diminuíram. Aproximou-se e reconheceu um anjo de pedra com cachos ondulantes que segurava um lírio e sorria suave e tristemente; olhou-o com uma estranha alegria, era o primeiro rosto que encontrava na cidade. Começou a limpálo com sopros leves, mas a alegria logo se esvaiu ao ver em suas vestes as cores gritantes, o dourado e o verniz cruel da indústria da fé. "E o sorriso no rosto lhe pareceu de repente tão morto quanto o cabelo ondulado demais". ${ }^{26}$

Para a psicanálise, silêncio é sinal de ruptura, que pode ser tanto um obstáculo para prosseguir a fala quanto uma impossibilidade total de produzir qualquer fala nesse momento.

Como obstáculo ao dizer, o silêncio em psicanálise pode indicar, por um lado, a presença de algo recalcado no inconsciente, de certo "não quero saber nada disso", mas as próprias associações - mesmo insensatas - que ocorrem após esse silêncio indicam o caminho da análise e seu prosseguimento.

Nesse ponto, o silêncio designa a ruptura expressa pelo Não, o Un de Unbewusst, de Unbegriff, como observa Lacan no Seminário XI, Os quatro conceitos fundamentais da psicanálise. A negativa radical presente no termo Unbewusst (inconsciente) tem como consequência, por outro lado, que seja difícil estabelecer seu conceito, forjando, pois, o termo Unbegriff, que seria "não o não conceito" - esclarece Lacan -, "mas o conceito da falta". ${ }^{27} \mathrm{Na}$ negativa radical se presentifica a ruptura, manifestada no silêncio.

A radicalidade da negativa do inconsciente é também responsável pela total impossibilidade de produzir uma fala. É um momento de angústia, sem palavras. Prosseguindo com Lacan: "A ruptura, a fenda, esse traço de abertura faz surgir essa ausência como o grito, que, podemos dizer, não se isola, não se perfila sobre fundo de silêncio, mas ao contrário, o faz surgir como silêncio". ${ }^{28}$

$\mathrm{Na}$ vacilação dessa estrutura inicial de ruptura, que concerne ao inconsciente, "surge o sujeito, alienado de sua história, no ponto em que a síncope do discurso conjuntase com seu desejo". ${ }^{29}$

Silêncio é também o modo do Isso (ou Id), instância muda, como aponta Freud na Segunda Tópica sobre o aparelho psíquico, com a dissecção em três instâncias: Eu, Isso e Supereu (ou Ego, Id e Superego). ${ }^{30}$ Essa nova estratificação se deve à necessidade de compreender certos impasses da clínica psicanalítica, que apresenta uma zona do inconsciente impossível de ser abordada pela palavra e pelo fluxo das lembranças e, no entanto, atuante, levando o sujeito a passar ao ato e a repetições.

Se, por um lado, podemos constatar que o inconsciente é estruturado como uma linguagem, por outro, o Isso (Id) é o inconsciente enquanto se cala, acrescenta Lacan. ${ }^{31}$

Silêncio da pulsão de morte, ${ }^{32}$ que tem sua função na estrutura.

\footnotetext{
${ }^{26}$ BÖLL. O anjo silencioso, p. 22.

${ }^{27}$ LACAN. Les quatre concepts fondamentaux de la psychanalyse, 22 jan. 1964, [s.p.]. (Tradução nossa).

${ }^{28}$ LACAN. Les quatre concepts fondamentaux de la psychanalyse, 22 jan. 1964, [s.p.]. (Tradução nossa).

${ }^{29}$ LACAN. Les quatre concepts fondamentaux de la psychanalyse, 22 jan. 1964, [s.p.]. (Tradução nossa).

${ }^{30}$ FREUD. O ego e o id, p. 37-39.

${ }^{31}$ LACAN. Les non-dupes errent, lição de 11 jun. 1974.

${ }^{32}$ FREUD. O ego e o id, p. 55-63.
} 
"É preciso ser tolo (dupe), isto é, colar, colar na estrutura". ${ }^{33}$ Essa afirmação de Lacan dirigida aos analistas surge no primeiro encontro do Seminário XXI, cujo título traz o equívoco: Les non-dupes errent, les noms du père (Os não tolos erram, os nomes do pai). Pluralizando os nomes do pai, Lacan aponta, no equívoco dos não tolos, o real da estrutura do inconsciente.

O analista se afirma como tolo da estrutura na medida em que, no campo do saber, resta uma parte não sabida, silenciosa, mas atuante, que na contingência do acaso nos surpreende e nos obriga a manter em função o desejo do analista. Essa é sua ética.

A escrita nos coloca em choque com essa hiância imposta ao ser falante, obrigandonos a bordejá-la com os elementos de que dispomos, quer na escuta do analista, quer pela "via subtrativa" (Badiou), no ato de recolher e depurar pequenos detalhes que poderão traçar um caminho de elaboração, fazendo veredas no silêncio.

Voltando à literatura: para um escritor, escrever é uma questão de ética. É preciso que o anjo silencioso seja portador de alguma mensagem, ainda que sobre seu próprio silêncio.

Assim é que Sebald, ao final de uma de suas conferências, traz o anjo de Paul Klee, cantado por Walter Benjamin em suas teses sobre a História.

Sebald compara o olhar que o escritor Kluge lança sobre sua cidade natal arrasada (Halberstadt) ao olhar desse anjo de olhos arregalados, um olhar fixo de pavor diante da catástrofe e da ruína acumulada a seus pés nos escombros que crescem até o céu. "Ele bem que gostaria de se deter, despertar os mortos e juntar os fragmentos. Mas uma tempestade sopra do paraíso emaranhando-se em suas asas, e é tão forte que o anjo não pode mais fechá-las". ${ }^{34}$

É o futuro, para o qual o anjo dá as costas.

Para onde se dirige o olhar do anjo? Silêncio.

Aí estão os trabalhos da arte e da escrita.

A)

\section{A B STRACT}

After W. G. Sebald's essays on the silence of German writers during after-war period, a question about the absence of writing in a culture of such a great literary expression and tradition arises. Regarding to the silence in front of the horror, this question is extended to the psychoanalytical field and related to the expression "passion to the real", in the philosopher Alain Badiou's words, who proposed also, in front of this state of things a "subtractive pathway".

\footnotetext{
${ }^{33}$ LACAN. Les non-dupes errent, lição de 13 nov. 1973, [s.p.]. (Tradução nossa).

${ }^{34}$ BENJAMIN citado por SEBALD. Guerra aérea e literatura, p. 64.
} 


\section{KEYWORDS}

W. G. Sebald, Alain Badiou, after-war period, writing, silence, psychoanalysis

\section{REFERÊNCIAS}

ANDRADE, Carlos Drummond de. Corpo. 16. ed. Rio de Janeiro: Record, 2002.

BADIOU, Alain. O século. Aparecida, SP: Ideias e Letras, 2007.

BÖLL, Heinrich. O anjo silencioso. São Paulo: Estação Liberdade, 2004.

FREUD, Sigmund. O ego e o id. In: FREUD, Sigmund. O ego e o id e outros ensaios (1923). Rio de Janeiro: Imago, 1969. p. 13-83. (Edição Standard Brasileira das Obras Psicológicas Completas de Sigmund Freud, v. XIX).

FREUD, Sigmund. Os chistes e sua relação como inconsciente (1905). Rio de Janeiro: Imago, 1969. (Edição Standard Brasileira das Obras Psicológicas Completas de Sigmund Freud, v. VIII).

LACAN, Jacques. Les non-dupes errent. Séminaire 1973-1974. Paris: Éditions de l'Association Lacanienne Internationale, [s.d.]. Publication hors commerce.

LACAN, Jacques. Le quatre concepts fondamentaux de la psychanalyse. Séminaire 1964. Paris: Éditions de l'Association Lacanienne Internationale, [s.d.]. Publication hors commerce.

LACAN, Jacques. Proposição sobre o psicanalista da escola (1967). In: ESCOLA LETRA FREUDIANA. Documentos para uma escola. Rio de Janeiro: Escola Letra Freudiana, [s.d.]. Publicação interna.

PIGLIA, Ricardo. Os sujeitos trágicos (literatura e psicanálise). In: PIGLIA, Ricardo. Formas breves. São Paulo: Companhia das Letras, 2004. p. 49-59.

SEBALD, Winfried Georg. Austerlitz. São Paulo: Companhia das Letras, 2008.

SEBALD, Winfried Georg. Guerra aérea e literatura. São Paulo: Companhia das Letras, 2011.

SEBALD, Winfried Georg. Os anéis de Saturno. São Paulo: Companhia das Letras, 2010. 